\title{
Resenha de Liberdade para aprender
} Review of Freedom to Learn

\section{Curriculum de Liberté pour apprendre}

\author{
Autor da Obra: Carl Ransom Rogers \\ Resenha da Obra: Liberdade para Aprender. $2^{\mathrm{a}}$ ed. \\ Belo Horizonte: Interlivros, 1973. \\ Ano da primeira edição: 1969
}

Thelmelisa LENCIONE QUEVEDO

\section{RESUMO}

A obra "Liberdade para Aprender", de Carl R. Rogers, partiu de questionamentos a respeito do sistema educacional. Ele escreveu aos profissionais da educação numa tentativa de motivar o desejo de mudança e a realização de algo concreto.

Para tanto, coloca à disposição tudo o que pôde ver de útil em sua própria experiência. Oferece exemplos que mostram como professores, trabalhando em níveis diferentes de ensino, descobriram maneiras de proporcionar liberdade para aprender, e apresenta consequências interessantes destes esforços. Aponta, ainda, atitudes a serem desenvolvidas por quem se interessa em ser "facilitador de aprendizagem", e recomenda métodos para desenvolver estas atitudes. Por fim, sugere um plano prático com vistas a mudanças revolucionárias no sistema de ensino.

Palavras-chave: autogestão, criatividade, liberdade para aprender, mudança

\section{ABSTRACT}

The book "Freedom to Learn" by Carl R. Rogers left questions about the educational system. He wrote that educators in an attempt to motivate change and the desire to accomplish something concrete.

For this purpose, available to all, he could see working in his own experience. Provides examples of how teachers, working at different levels of education, have found ways to provide freedom to learn, and has 
interesting consequences of these efforts. Also the book shows the attitudes to be developed by those interested in being a "learning facilitator", and recommends methods to develop these attitudes. Finally, it suggests a practical plan with a view to revolutionary changes in education.

Index terms: self-management, creativity, freedom to learn, change

\section{RÉSUMÉ}

L'œuvre de Carl R. Rogers, «Liberté pour apprendre », a partir de questions sur le système d'éducation. Il a ecrit aux professionels de l'éducation dans une tentative de motiver le desire de changement et la réalisation de quelque chose de concret.

Pour cela, Carl met à la disposition tout ce qu'il a pu voir d'utile dans sa propre expérience. Il offre des exemples qui montrent de quel manière des professeurs, qui travaillent à différents niveaux d'enseignement, ont découvert des maniéres de proportionner la liberté pour apprendre, et l'auteur, aussi, présente les résultats intéressants de ces efforts. Rogers indique, aussi, des attitudes à être développées pour ceux qui s' interessent à rendre facile l'apprentissage ", et recommande des méthodes pour développer ces attitudes. À la fin, il suggère un plan pratique pour un changement révolutionnaire dans le système d'enseignement.

Mots-clefs: auto-gestion, criativité, liberté pour apprendre, changement.

Rogers (1902-1987) é considerado precursor da corrente humanista, não diretiva, em educação. Sua teoria desenvolveu-se a partir de sua própria experiência profissional, projetando o que viveu para explorar a investigação científica.

"Liberdade para Aprender" teve como objetivo inicial compendiar tudo o que o autor vinha escrevendo aos educadores e acabou incluindo ideias novas, desenvolvendo trabalhos anteriores e tratando de questões acerca de um modelo revolucionário de educação. A obra é dividida em cinco partes. As duas primeiras são práticas, oferecem canais à professores que poderão, por si mesmos, arriscar-se em experimentações junto a seus 
alunos. A terceira contém bases conceituais para tal experimentação. A quarta parte lança suportes pessoais e filosóficos de toda a abordagem do tema e, por fim, a quinta convida o leitor a se engajar em um programa de mudança no sistema de ensino.

Rogers parte de questionamentos acerca do objetivo da aprendizagem, e do papel da escola frente às questões sociais. Para ele, o propósito da aprendizagem no mundo moderno deveria ser o de libertar a curiosidade, permitir que as pessoas assumam o encargo de seguir novas direções ditadas por seus próprios interesses, desencadear o senso de pesquisa e abrir tudo à indagação e à análise.

O autor expõe duas espécies de aprendizagem: a "espécie de tarefa": imposta, sem significação pessoal, lida apenas com o cérebro, não tem relevância para a pessoa como um todo. E a "aprendizagem experiencial", auto-iniciada, tem influência significativa sobre o comportamento, dá origem a aprendizes autoconfiantes e criativos.

Rogers discorda de métodos que enfatizam desempenhos intelectuais, desvalorizando aspectos intuitivos e emocionais. Para além do ato de aprender, a obra se inscreve na problemática da produção de saber; não apenas naquela de sua "simples" absorção, mas articulado com os interesses pessoais como fatores atuantes na motivação para a construção do conhecimento.

Rogers valoriza a aprendizagem experiencial, e acredita que os seres humanos têm natural potencialidade para aprender, são curiosos a respeito do mundo em que vivem. Sua premissa é a de que a aprendizagem é favorecida ao máximo quando o aluno escolhe livremente sua orientação. Neste sentido, a aprendizagem é eficaz quando auto-iniciada e articulada a interesses pessoais - é colocando o estudante em confronto direto com problemas práticos, reais para si, que ele se motiva para a construção do conhecimento. Quando se permite aos alunos idearem a sua 
maneira de atingir novos conhecimentos, os conceitos que adquirem por esse processo têm maior profundidade e compreensão.

$\mathrm{O}$ professor que se preocupa em facilitar a aprendizagem experiencial organiza seus esforços de modo muito diferente do convencional, e é chamado por Rogers “facilitador da aprendizagem”. Para proporcionar este tipo de aprendizagem, há métodos que não se empregam como faz um professor tradicional: não se estabelece deveres de casa, nem idênticos para todos, não há testes padronizados, não se determina leituras; não há provas obrigatórias, e o professor não se responsabiliza sozinho pelas notas.

O papel do facilitador é se empenhar em tornar disponíveis recursos para a aprendizagem, da mais ampla ordem possível. Considera-se como recurso, põe seu saber à disposição do aluno, mas não se impõe a ele. Procura trazer à tona tanto os propósitos individuais, quanto os mais gerais do grupo. É capaz de ser autêntico, sem ostentar aparências - se torna um membro do grupo, exprimindo suas opiniões, tanto quanto sentimentos pessoais. $\mathrm{O}$ mais importante não tem haver com o treinamento, mas com a atitude. O facilitador precisa criar um clima de confiança e aceitação em sala de aula - não significa gostar do aluno, apenas deve aceitá-lo como um ser humano imperfeito: com tudo o que o outro é, ele é merecedor de crédito. Neste sentido, permite liberdade para idéias fora do comum, pois acredita que, ao ser livre, o aprendiz se torna curioso, passa a perseguir objetivos próprios, e a aprendizagem se torna uma busca excitante, não uma mera acumulação de informações. O diferencial está na habilidade para acompanhar, mais que conduzir.

Ao compartilhar a miscelânea de uma bagagem de aprendizagens, Rogers enfatiza que cada professor desenvolve o seu modo de permitir liberdade, adaptáveis a seu estilo, mas reconhece que o iniciante se interessa por saber como outros fizeram e quais resultados tiveram. Então, expõe 
exemplos de professores que se empenharam em dar liberdade para aprender.

Apresenta o exemplo da Sra. Barbara J. Shiel, professora de uma classe de sexto ano, que enfrentava problemas de desmotivação e indisciplina dos alunos. Ela iniciou uma nova experiência dando liberdade aos aprendizes, na medida em que podia fazê-lo, pois não era livre para descartar o currículo estatal. A cada início da semana assinalava temas que os alunos deveriam desenvolver para que levassem isso em conta ao elaborar seus projetos: cada um escolhia as áreas em que pretendia trabalhar. Chamou o programa de autodirigido: dirigido no sentido de que tinham que trabalhar dentro do currículo, e "auto" porque cada aluno é responsável pelo seu próprio planejamento dentro desta estrutura básica.

Desenvolveu-se um projeto interessante, com resultados surpreendentes: os alunos motivaram-se a pesquisar assuntos que lhes atraiam, a iniciativa e a criatividade germinaram, passaram a ter responsabilidade. Dia a dia cresceram em relação ao orgulho por se autorrealizarem, tornaram-se mais conscientes de sua capacidade e começaram a se interessar mais pela escola e por seu próprio progresso. Os que antes tinham que ser tratados por medidas disciplinares desenvolveram normas de comportamento por si, e agiam de acordo com esses padrões.

O segundo exemplo é de um professor universitário, Sr. Volney Faw. Ele apresenta a liberdade para aprender em instituições que atuam dentro de limites educacionais rígidos. Se, por um lado, a liberdade é díspare em relação ao rigor acadêmico, por outro, em sua experiência, ele mostra como os dois se uniram, e se mantiveram.

O Sr. Faw inicia sua experiência apresentando aos alunos uma metodologia na qual descrevia alguns elementos básicos de um curso: Pessoas. Interações. Processos. Conteúdo. Pressão Institucional. As "pessoas" e as "interações" foram envolvidas por um ambiente em que se valorizavam expressões espontâneas e autênticas. Os "processos" seriam os 
meios utilizados pelos alunos para articular seus interesses e as exigências institucionais. O "conteúdo" tem caráter instrumental e a "pressão institucional" diz respeito às expectativas de outros (escola, pais) que deverão ser consideradas. A partir destes elementos são descritos exemplos da aplicação da metodologia criada pelo professor, que é facilmente adaptável, até mesmo em instituições de normas extremamente rígidas.

O terceiro exemplo exposto por Rogers se refere a uma experiência pessoal em um curso que acabara de ministrar para estudantes de um programa de doutoramento em Liderança Educacional e Comportamento Humano.

Rogers procurou promover o clima de liberdade que tanto insistia em manter pelo resultado que proporcionava. No entanto, reconheceu que dar liberdade pode ser arriscado - se oferecer muita liberdade, isto suscita ansiedade, frustrações e raiva. Então, sugere um grau de liberdade que pareça autêntico e cômodo. A partir disso inicia por estruturar o curso, sem intervenções demasiadas, mas apresentando termos convencionais e exigências.

Os alunos foram informados a respeito de seminários que deveriam apresentar e, para tanto, foi oferecida a bibliografia do curso, pensada a partir de variadas referências, com o intuito de fornecer informações e não de exigir obrigatoriedade quanto à leitura. Se por um lado nenhuma leitura era obrigatória, por outro, deveriam todos entregar, ao fim do programa, uma lista do que leram e anotações da maneira como fizeram a leitura, assim como uma auto-avaliação e a indicação de uma nota.

As impressões finais a respeito das experiências do curso foram de um fortalecimento da autoconfiança, e de uma valorização a respeito das próprias experiências, o que levou os alunos a acreditarem mais na própria capacidade e a desenvolverem um conhecimento sobre a temática tratada, que não se limitou à intelectualidade. 
Ao apresentar estes exemplos, Rogers insiste no fato de que não deseja, com isso, instruir leitores sobre o que pensar ou fazer, mas convida o leitor a decidir, por si, se o que lê tem importância para sua profissão, e para a sua vida.

A obra finaliza com um plano prático de mudança para o sistema educacional, facilitado pela experiência de grupos. A idéia é que façam parte do grupo principalmente pessoas em posição de mando nas instituições - é preferível a participação voluntária, mas se possível a administração deve envolver toda a equipe acima de certo nível porque, digamos que um dirigente participe do grupo e retorne para sua escola com propostas de mudança. Se lá as pessoas são rígidas, e o sistema "bem regulamentado", há duas opções: ou ele volta decepcionadamente a seu comportamento anterior, ou se torna uma influência perturbadora na instituição.

O grupo inicia esperando que lhe seja dito como se comportar, ficam frustrados quando percebem que eles próprios determinarão a forma pela qual o grupo funcionará. O facilitador apenas estimula a interação, permitindo máxima liberdade para expressão pessoal, de modo que, gradualmente, cada integrante deixe de lado suas defesas, indo abertamente ao encontro dos outros integrantes.

É surpreendente a qualidade das relações que se desenvolvem. Administradores que trabalham juntos há anos descobrem que jamais haviam se conhecido e sentimentos negativos que prejudicaram planos e trabalhos, vêm à tona com segurança para serem compreendidos. Ao ser compreendido, o indivíduo se abre para trocas que permitem a cada pessoa identificar o modo como é vista pelos outros. Isto facilita comunicações mais orientadas a objetivos abertamente declarados, o que capacita a pessoa a lidar com conflitos ao invés de sepultá-los sob novos regulamentos ou evitá-los de outras maneiras. Ao diminuir a necessidade da proteção de regras burocráticas, as pessoas se tornam mais democráticas e dispostas a 
correr o risco de novas direções. Muitos relatam suas experiências em grupo como as de aceitação mais positivas de suas vidas. A popularidade destas experiências repousa tanto no calor emocional que geram como em sua capacidade de facilitar o crescimento pessoal.

Ficou evidenciado que a orientação que permeia esta obra se situa num contexto pessoal, filosófico e de valores, cujo foco é a pessoa aberta à experiência, capaz de se engajar na construção do próprio conhecimento. Rogers acreditava que existe em cada indivíduo uma capacidade natural para a aprendizagem e algo que o impulsiona à atualização de potencialidades em direção à seu próprio desenvolvimento.

\section{Referências Bibliográficas}

FADIMAN, J. \& FRAGER, R.. Teorias da personalidade. São Paulo: Harbra, 1986.

ROGERS, C. R. Liberdade para aprender. Trad. de Edgard de Godói da Mata Machado e Márcio Paulo de Andrade. $2^{\text {a }}$ ed. Belo Horizonte: Interlivros, 1973.

Texto recebido em janeiro de 2012.

Texto aprovado para publicação em janeiro de 2012.

\section{Como citar este texto:}

QUEVEDO, T. L.. Resenha de Liberdade para aprender. Revista Acolhendo a alfabetização nos países de língua portuguesa, Brasil, São Paulo, volume 1, $\mathrm{n}^{\circ}$. 12, p. 148 - 155 , Mar. 2012. Disponível em: $<$ http://www.acoalfaplp.net>. 